DOI: http://dx.doi.org/10.17793/rdd.v3i5.551

\title{
3. SOBRE DIREITOS E A HUMANIDADE DO DIREITO N'O MERCADOR DE VENEZA
}

\section{ABOUT RIGHTS AND THE HUMANITY OF RIGHTS IN THE MERCHANT OF VENICE}

\section{Renato Selayaram ${ }^{1}$}

Resumo: $\mathrm{O}$ artigo procura analisar os aspectos jurídicos da clássica obra de Shakespeare e a complexa relação entre seus personagens. A influência do direito e da moral, vislumbrando suas diferentes nuances, especialmente Shylock - um dos personagens mais atraentes do teatro de todos os tempos.

Palavras-chave: direito, contrato, moral, literatura

Abstract: El artículo analiza los aspectos legales de la clásica obra de Shakespeare y la compleja relación entre sus personajes. La influencia de la ley y moral, al ver sus diferentes matices, especialmente Shylock - uno de los personajes más atractivos del teatro de todos los tiempos.

Palabras-clave: Ley, convenio, moral, literatura.

\section{Introdução}

A base de uma sociedade civilizada consiste no respeito ao direito. O que sempre me fascinou n'O Mercador de $V_{e n e z a}{ }^{2}$ é o fundo legal da obra. Tanto no início da trama - a celebração de um contrato - como a sua resolução - o debate jurídico em um tribunal sobre sua validade ou não, permitem analisar a obra do ponto de vista jurídico e exercitar o uso de alguns institutos legais, para além da ficção.

O enredo gira em torno de dois personagens principais: um judeu rico e usurário, e uma mulher - a tolerante e apaixonada Portia, os quais representam dois dos grupos mais discriminados na época, judeus e mulheres. Devemos recordar que no momento em que o bardo escreveu esta peça, foi executado o médico pessoal da rainha Elizabeth I, o hispano-judaico Rodrigo Lopez, acusado,

\footnotetext{
${ }^{1}$ Advogado, Pós-graduado na Academia de Direito Internacional de Haia, Especialista en Ciências Políticas, Mestre em Direito, Professor no Cesuca. E-mail: selayaram@hotmail.com .

${ }^{2}$ SHAKESPEARE, William. O mercador de Veneza. Trad. de F. Carlos de Almeida Cunha e Oscar Mendes. São Paulo: Abril S.A. Cultural e Industrial, 1979, págs. 280-367.
} 
sem provas, de tentar envenenar a rainha britânica a pedido de Filipe II, rei espanhol. Sua execução em 07 de junho de 1594 em Tyburn provocou uma onda de anti-semitismo no país.

De modo geral, a comédia narra como Bassanio, um jovem de ascendência ilustre mas sem fortuna, procura o amor de Portia, uma órfã rica que só se casará com o pretendente que decifre o enigma das três caixas - uma de ouro, outra de prata e outra de chumbo - de acordo com o testamento de seu falecido pai, e escolha aquela que contém o retrato da jovem. Para tanto, poder participar do evento, é necessário que pague a importância de três mil ducados, dinheiro que não possui e solicita a Shylock, o agiota. Quem se obriga pelo empréstimo é Antonio, o mercador de Veneza do título, amigo de Bassanio e responsável pela obtenção do empréstimo por sua capacidade econômica, e ao contrário deste, um comerciante proeminente, sendo acordado que a devolução do montante obtido será em três meses, prazo estimado por Antonio para a chegada dos navios com mercadorias encomendadas a Veneza e assim saldar a obrigação. Para formalizar o crédito, assina um contrato, ante um Tabelião, estipulando que o não reembolso do montante tomado, na data e local estipulados, o credor - Shylock - pode tomar uma libra de carne, aproximadamente quatrocentos e cinquenta gramos, do devedor.

Como podemos ver, estamos ante um contrato de mútuo, com data certa de devolução da soma emprestada e uma cláusula penal a favor do credor em caso de inadimplemento por parte do devedor (a libra de carne de Antonio). Do ponto de vista legal, pois, é um acordo contratual em que rege a máxima latina pacta sunt servanda, traduzida livremente como o pacto é a lei entre as partes, princípio do direito contratual ainda vigente.

Vencido o prazo fixado no contrato, Antonio não cumpre a obrigação assumida, já que os navios com as mercadorias de sua propriedade não chegaram ao porto por haverem naufragado, sendo, portanto, incapaz de pagar a dívida. Por esta razão Shylock exige a execução da cláusula penal a seu favor por inadimplência do devedor, recorrendo ao Tribunal de Veneza em busca da tutela judicial.

Admitida a demanda ante a máxima autoridade, o Doge de Veneza, as partes são citadas para que seja dado início ao julgamento, sendo proposto antes às partes um acordo, sabedor aquele que a lei será extremamente rigorosa e que deverá ser cumprida ou a República perderá um de seus maiores bens, a 
segurança jurídica, o pilar básico de qualquer governo. Quem poderia confiar em Veneza se não fossem cumpridas suas próprias leis? Antonio assim o reconhece quando diz

O Doge não pode impedir o curso da lei. As garantias que os estrangeiros encontram em nosso meio, em Veneza, não poderiam ser suspensas sem que a justiça do Estado ficasse comprometida aos olhos dos mercadores de todas as nações cujo comércio fez a riqueza da cidade.

O pedido de Shylock é bastante concreto: não está fundado no pagamento da dívida, seja esta em seu valor original ou duplicada, como é proposto em conciliação, senão na execução da cláusula penal. Sua proposta é: não cumpriste com o pagamento no momento oportuno, exijo como ressarcimento uma libra de tua carne,

Shylock - Quero que as condições de meu contrato sejam cumpridas; jurei que seriam executadas. Chamaste-me de cão quando não tinhas razão alguma para fazê-lo; porém, visto que sou um cão, tem cuidado com meus dentes. O Doge me fará justiça. (...)

Até este momento a razão e o direito parecem assistir a Shylock. O Doge de Veneza se mostra impotente para negar o pedido do velho agiota sem cair em descrédito, pois a cidade vive do comércio e suas leis devem ser respeitadas para ter credibilidade ante outros Estados. Recordemos que Veneza, desde a Alta Idade Média, se tornou muito rica mediante seu controle do comércio entre a Europa e os países do Mediterrâneo oriental. Por volta de 1410, tinha um armada de 3300 navios (tripulados por 36000 homens) ${ }^{3}$. E foi uma das cidades do norte da província itálica onde começou o reflorescimento do direito romano, utilizado para a solução dos conflitos que surgiam como decorrência do comércio pujante da cidade.

Parece que não restava outro remédio ao mais alto magistrado da república senão executar o que estava pactuado. Eis que, neste momento dramático, Portia irrompe no Tribunal, disfarçada do jovem advogado Baltasar, a fim de assumir a defesa de Antonio ${ }^{4}$. No início, parece dar razão ao agiota, seguindo as

3 CAMPAgnANO, Anna Rosa. Judeus de Livorno: sua língua, memória e história. São Paulo: Humanitas, 2007, p. 41.

${ }^{4}$ Balthasar/Portia se apresenta ao Tribunal de Veneza como uma espécie de amicus curiae, um "amigo da corte", para ajudar a lançar luzes sobre o caso, mas se trata de um engano, dado que no fundo o que busca é defender Antonio. 
regras do direito contratual e reconhecendo que todo contrato deve ser cumprido em conformidade com o estipulado ao dizer uma libra de carne desse mercador te pertence. O tribunal te adjudica essa libra e a lei ordena que ela te seja dada. E podes cortar-Ihe essa carne do peito. O tribunal o autoriza e a lei o permite.

Mas na parte final de seu discurso, realiza um giro espetacular de 180 graus, ao assinalar que se é certo que a cláusula penal deve ser executada tal como está pactuada, não é menos certo que o contrato não prevê o derramamento de sangue do devedor para a obtenção da libra de carne nem que seja retirado um gramo a mais do que foi estipulado e muito menos ainda seja posta em risco a sua vida para o cumprimento da obrigação:

Portia - Espera um momento. Ainda não é tudo. Esta caução não te concede uma só gota de sangue. Os termos exatos são: uma libra de carne. Toma, pois, o que te concede o documento; pega tua libra de carne. Mas, se ao cortá-la, por acaso, derramares uma só gota de sangue cristão, tuas terras e teus bens, segundo as leis de Veneza, serão confiscados em benefício do Estado de Veneza.

Em outras palavras, a cláusula penal a favor de Shylock é inexeqüível, pois se trata de uma impossibilidade jurídica, e é uma impossibilidade legal porque colide com regras de ordem pública de caráter imperativo que protegem a vida e a saúde das pessoas. Antonio é cidadão veneziano e, por extensão, cristão velho (ou cristão-puro, conceito ideológico que pretendia designar o segmento majoritário das populações), tendo direitos garantidos pelo Estado, os quais estão acima do que foi acordado. O que Balthasar/Portia demonstra com seus argumentos jurídicos é que a cláusula penal é ineficaz desde o início e é nula de pleno direito por violar disposições de ordem pública que cuidam da integridade física da pessoa.

Mais do que o famoso monólogo do agiota, quando ele diz que Um judeu não tem olhos? (...) Se nos cortam, não sangramos? Se nos fazem cócegas, não rimos? Se nos envenenam, não morremos?, o intenso debate jurídico entre os personagens faz desta passagem de O Mercador de Veneza, um dos destaques da literatura universal, do ponto de vista jurídico.

\section{II. $\quad$ perigo da hierarquização}


N'O Mercador de Veneza, sem dúvida o trabalho mais jurídico de Shakespeare, observamos o surgimento de uma impressão digital de incompreensão lamentavelmente repetida, com crueldade extrema, no curso da história ocidental: a perda de perspectiva no cumprimento do mandato, o estabelecimento de um olhar valorativo do ordenamento positivo - percepção nada ingênua que necessariamente segrega no ato de sua imposição aquilo que uma determinada pessoa ou grupo é e não o que faz.

Em sua necessidade de expor o óbvio - o judeu é um homem, os cristãos também o são - Shylock, o marginalizado, aceita o gesto de marginalizaçãodiferenciação, que o exclui e, a partir de então, encontra na exclusão que the é imposta, a legitimação para sua pretensão de vingança. Enquanto sua humanidade não seja aceita pelo ordenamento jurídico vigente, não se lhe pode exigir respeito à humanidade dos outros.

Como em tantos outros lugares na Europa, em Veneza, aqueles que professavam a fé judaica eram circunscritos aos limites de um gueto, os portões da cidade os excluiam, quando a noite chegava os portões eram fechados com cadeados. Um muro de pedra manifestava, assim, o limite da legitimidade.

Como vemos, de todos os homens, o direito escolhia alguns para serem seus sujeitos, no exemplo utilizado aqueles que participavam do credo cristão, e estabelecia um espaço de marginalidade comum a todos aqueles que não fossem seu objeto.

Toda classificação expõe uma ordem hierárquica e traça ao menos uma linha divisória. Aceita e expele, acolhe e desconhece, divide e, no mesmo ato, estabelece o limite fora do qual se estende o império da alienação e da diferença.

Podemos observar que ao longo da história o estabelecimento de limites na atribuição de legitimidade, sempre arbitrária e ofensiva, faz com que, conforme mostra Shakespeare, os marginalizados, deslustrados pelo direito, terminem por assumir os mesmos parâmetros que serviram para justificar sua exclusão.

O outro, os outros, não serão mais do que aquele ou aqueles que se atrevam a expor, desde a perspectiva de quem estabelece a classificação, uma absoluta falta de pertencimento. Desse modo, a sua mera existência como um estranho, importa a prévia adoção de um ponto de vista: não existe classificação possível se não houver, previamente, um classificador, quem detenha ou usurpe a faculdade de dividir, de impor-se como representante do núcleo de diferenciadores. 
Nada mais visível desta face do que o status quo vigente na Idade Média, sob o ponto de vista Senhor e servo, Nobre e vassalo.

Bobbio diz que a violência pode ser direta ou indireta. É direta quando atinge de maneira imediata o corpo de quem a sofre. É indireta quando opera através de uma alteração do ambiente físico no qual a vítima se encontra, como, por exemplo, o fechamento de todas as saídas de um determinado espaço, ou através da destruição, da danificação ou da subtração dos recursos materiais. Em ambos os casos, o resultado é o mesmo: uma modificação prejudicial do estado físico do indivíduo ou grupo que é alvo da ação violenta. ${ }^{5}$

À paz perpétua ${ }^{6}$, obra Kantiana, é, na realidade, a meta a ser atingida por meio do respeito e exercício dos princípios e normas estabelecidos nesse fictício tratado de paz. O adjetivo perpétua diferencia o tratado em questão dos tratados de paz habitualmente firmados, que não passam de meros armistícios que cuidam de regular a melhor forma jurídica para a cessação das hostilidades entre os inimigos ${ }^{7}$.

O caso que aqui estamos tratando, nos mostra que a arbitrariedade ocultase por trás de uma divisão ontológica: reconhecer somente a alguns os direitos que são comuns a todos os seres humanos. Aos demais, vale dizer, Shylock, são atribuídos direitos reconhecidos como inumanos. Admitir que certos direitos sejam assim reconhecidos importa negar-Ihes sua existência como direitos.

O homem, pelo fato de integrar o gênero humano, é detentor de dignidade, a qual é qualidade ou atributo inerente a todos os homens, decorrente da própria condição humana, o que o torna credor de igual consideração e respeito por parte de seus semelhantes ${ }^{8}$.

A meu juízo, o Direito Fundamental do homem é o direito à sua realização integral como ser humano. Qualquer das suas dimensões que se pretendesse amputar estaríamos negando sua condição de ser humano.

\section{Direito e moral}

\footnotetext{
${ }^{5}$ BOBBIO, N.; PASQUINO, G.; MATTEUCI, N. Dicionário de política. 7ạ ed. Brasília: UNB, 1995, p. 1291-1292.

${ }^{6}$ A obra À paz perpétua foi escrita pelo filósofo alemão Immanuel Kant em 1795, cuja grande questão era como assegurar que os Estados Nacionais europeus pudessem estabelecer entre si um quadro de paz duradoura.

${ }^{7}$ ALMEIDA, Guilherme de Assis. Direitos humanos e não-violência. São Paulo: Atlas, 2001, p. 27.

${ }^{8}$ SARLET, Ingo Wolfgang. Dignidade da Pessoa Humana e Direitos Fundamentais na Constituição Federal de 1988. Porto Alegre: Livraria do Advogado, 2001, p. 60.
} 
A moral é, como o direito, um sistema objetivo de normas que tem por missão ordenar a conduta do homem. Existem inegáveis relações entre um e outro sistema. Uma norma tipicamente jurídica, como a que ordena não roubar e pune a quem rouba é, ao mesmo tempo, uma norma moral. Outra norma de direito, a que afirma que as obrigações assumidas devem ser cumpridas, é também um preceito moral ${ }^{9}$.

A vida é o uso e não a produção de coisas e o escravo serve apenas para facilitar este uso. O amo é o senhor do escravo e este, pelo contrário, não é apenas um escravo para o mestre, mas lhe pertence por inteiro. Isso mostra que o escravo é, em si, o que pode ser. Aquele que por uma lei da natureza não se pertence, mas, sem deixar de ser homem, pertence a outro, é naturalmente escravo. Assim, o escravo é propriedade alheia, e a propriedade é um instrumento necessário para a existência ${ }^{10}$. Há indivíduos na espécie humana tão inferiores a outros como o corpo para a alma ou a fera para o homem ${ }^{11}$. Assim exprimia Aristóteles.

Podemos observar, na desconstrução das afirmações aristotélicas que:

1. O escravo era considerado, na sua obra, como ser humano, inobstante aceitar, o fato de pertencer a outro homem.

2. A natureza humana não implicava, por si só, sua condição de sujeito de direito. 0 homem-escravo, em sua condição de objeto, não era possuidor de direitos.

3. O conceito de espécie humana se achava sujeito à imposição de hierarquização, isto é, nela eram identificados homens superiores e homens inferiores.

Esta é a perspectiva que retoma Skakespeare n'O Mercador de Veneza. Muito além da valoração convencional que sobre certos comportamentos humanos se possa fazer, deixo claro entender a dignidade humana como inalienável, mesmo antes de vir a ser reconhecida por um ordenamento jurídico e, inclusive, excedendo aos limites de qualquer potestade estatal.

Toda estrutura jurídica se assenta sobre o cumprimento da palavra empenhada. As partes contratantes possuem expectativas distintas em relação ao

\footnotetext{
${ }^{9}$ ARÉCHAGA, Eduardo Jimenez; FERRAND, Martín Risso. Introducción al derecho. Montevideo: Fundación de Cultura Universitária, 2007, p. 15. Tradução do autor.

${ }^{10}$ ARISTÓTELES. Política. Tradutor: Nestor Silveira Chaves. São Paulo: Saraiva, 2010, p. 16.

${ }^{11}$ ARISTÓTELES. Política. Tradutor: Nestor Silveira Chaves. São Paulo: Saraiva, 2010, p. 17.
} 
pactuado e está implícito que devem asumir a responsabilidade de cumprir o que prometeram.

Pelo fato de a cláusula penal atentar contra a vida e a saúde do devedor, a defesa, representada por Portia, travestida de Baltasar, pede como compensação econômica a metade dos bens de Shylock em favor de Antonio, o que, no caso, pode ser interpretado como uma reconvenção, e que a outra metade seja confiscada em favor do Estado veneziano, pelo fato de o credor haver demandado de forma a agredir o direito vigente, as normas de ordem pública de caráter imperativo.

Poderia ser alegado em defesa do credor que o dano nunca chegou a se materializar, que Antonio nunca pôs em perigo sua vida ou saúde, em razão do fato de que o credor não pode executar a cláusula penal. Entretanto, muito embora não tenha havido um dano físico, pode ser argüido que houve um dano moral. Shylock expôs Antonio a um juízo, a um questionamento sobre sua reputação, pondo seu nome e reputação ilibada de comerciante em xeque, quando o que reivindicava judicialmente era algo impossível de executar. Por conseqüência, o temor de Antonio de perder a vida por cumprir a cláusula lhe ocasionou um sofrimento inimaginável, merecendo um ressarcimento econômico pelo dano emocional sofrido.

Vemos na obra que existe uma tensão entre o sentido de justiça e o de legalidade. O credor funda sua pretensão literalmente no que diz a lei, ou o que foi avençado contratualmente, não importando se é justo ou injusto, não importa se é a custa da vida de um ser humano, apenas no que está pactuado. Como vemos, ao final a tensão será resolvida graças a uma burla, pois não importa quem tenha razão ou de que lado se encontra a justiça, senão quem é mais hábil para ganhar o processo.

Em diferentes trabalhos de expressão artística ou mitológica, o protagonista deve resolver o enigma que the é apresentado, ao custo de sua própria vida se assim não o fizer. Como na própria vida, trabalhando e selecionando a melhor de uma ou outra possibilidade de uma aposta.

A título de exemplo, lembramos duas passagens de grandes obras, da mitologia e da literatura. Ante a disputa entre as deusas Hera, Atena e Afrodite sobre quem era a mais bela, Zeus não quis ser o juiz para não descontentar as deusas, ordenando, então, que o príncipe troiano Páris, à época sendo criado como um pastor ali perto, resolvesse a disputa. Para ganhar o título de "mais bela", Atena 
ofereceu-Ihe poder na batalha e sabedoria, Hera ofereceu-lhe riqueza e poder e Afrodite o amor da mulher mais bela do mundo. Páris optou por Afrodite, ganhando sua proteção e o ódio das outras duas deusas, contra si e contra Tróia.

Na peça Édipo Rei, de Sófocles, o protagonista deve decidir entre salvar Tebas descobrindo o enigma da Esfinge, que o tornaria um herói, e salvar o seu próprio destino, do qual não pode fugir. A esfinge propõe um enigma a partir de três opções:

Qual é o animal que de manhã anda sobre quatro pés, ao meio-dia sobre dois e à noite sobre três? É o homem, que na infância arrasta-se sobre os pés e as mãos; na idade adulta mantém-se sobre os dois pés; e na velhice precisa de um bastão para poder andar.

Assim, o que vemos são os personagens envolvidos na peça Shakespeariana tratando de burlar uns aos outros, valendo-se, para tanto, do direito.

Há na obra uma tensão entre o sentido de justiça e legalidade. Justiça entendida como caridade, comiseração em relação ao outro, tentando fazer com que Shylock pense de modo racional, a fim de que desista de suas pretensões sanguinárias. Em contraposição, este basea-se literalmente no que diz a lei, ou pactuado contratualmente. Se é certo ou errado não importa, tampouco se é à custa da vida de um ser humano, mas no que está acordado; e, como podemos ver, no final a tensão entre a reivindicação de Shylock e a absolvição de Antonio será resolvida graças a um embuste: não interessa quem está certo ou de que lado a justiça se encontre, mas quem é mais hábil para ganhar o processo.

\section{Como conclusão}

Finalmente, e como já foi referido por outros autores, há uma crítica social velada de Shakespeare para com os cristãos que se escondiam atrás de seu status de herdeiros de Cristo para tirar vantagem dos outros, neste caso dos judeus que, como Shylock, se dedicavam a um ofício condenado pela Igreja Católica aos seus fiéis. É como se que os descendentes de Abraão tivessem o monopólio de emprestar dinheiro a juros (um cristão só poderia emprestar uma soma em dinheiro sem cobrar juros), mas naqueles anos a proibição estava começando a ser flexibilizada pela Reforma Protestante. 
Shylock pede justiça como qualquer cidadão - o que hoje denominamos tutela jurisdicional efetiva - com um pedido específico: que seja executada a cláusula penal e, aparentemente, Ihe são abertas as portas da administração da justiça. Mas ao final, esta aparente abertura do Tribunal para ouvir seu pedido se transforma em zombaria e desapropriação (Shylock, perplexo, exclama: Is that the law? Essa é a lei?). O aparato legal que move o credor, em seguida, se volta contra ele. Shylock toma uma dimensão trágica no final, não só perde o juízo, mas também seus bens e sua religião, sendo forçado a se converter ao cristianismo, para evitar perdê-los todos; e até mesmo sua própria filha foge com um cristão. Por isto, este personagem da literatura é estudado e admirado, um personagem muito difícil de esquecer.

\section{Referências bibliográficas}

ALMEIDA, Guilherme de Assis. Direitos humanos e não-violência. São Paulo: Atlas, 2001.

ARÉCHAGA, Eduardo Jimenez; FERRAND, Martín Risso. Introducción al derecho. Montevideo: Fundación de Cultura Universitária, 2007.

ARISTÓTELES. Política. Tradutor: Nestor Silveira Chaves. São Paulo: Saraiva, 2010.

BOBBIO, N.; PASQUINO, G.; MATTEUCI, N. Dicionário de política. $7^{a}$ ed. Brasília: UNB, 1995.

CAMPAGNANO, Anna Rosa. Judeus de Livorno: sua língua, memória e história. São Paulo: Humanitas, 2007.

SARLET, Ingo Wolfgang. Dignidade da Pessoa Humana e Direitos Fundamentais na Constituição Federal de 1988. Porto Alegre: Livraria do Advogado, 2001.

SHAKESPEARE, William. O mercador de Veneza. Trad. de F. Carlos de Almeida Cunha e Oscar Mendes. São Paulo: Abril S.A. Cultural e Industrial, 1979.

(Artigo recebido em 13/12/2013 e aprovado para publicação em 30/12/2013) 